Article

\title{
It's Like Growing Roots inside Something Deeply Familiar: An Explorative Qualitative Study of Anthroposophic Mantra Practice and the Subsidiary Exercises
}

\author{
Terje Sparby \\ Department of Psychology and Psychotherapy, Witten/Herdecke University, Alfred-Herrhausen-Straße 50, \\ 58448 Witten, Germany; terje.sparby@uni-wh.de
}

Received: 14 June 2018; Accepted: 10 August 2018; Published: 16 August 2018

\begin{abstract}
Anthroposophic meditation is unique in that it arises within a European context and emphasizes cognition, self-development, and sociocultural renewal. This article presents the perceived effects of two of the most common Anthroposophic meditation practices within the current sample $(\mathrm{N}=30)$. The first, Anthroposophic mantra practice, seeks to connect the practitioner to a spiritual reality. The second, the so-called subsidiary exercises, focuses on developing clear thinking, willpower, and certain virtues that support meditative development, while also deepening the connection between the meditative and daily life of the practitioner. Additionally, the subsidiary exercises may represent a way of reducing negative effects or handling potential challenges arising from meditation. Some themes overlap with the findings of previous studies on meditation. Other themes, such as cognitive insights, the development of virtues through meditative or spiritual practice, and the potential for beneficial impact on one's sociocultural environment, open up new avenues of study.
\end{abstract}

Keywords: meditation; Anthroposophy; cognition; personal development; challenging meditation effects

\section{Introduction}

Anthroposophy has mostly remained on the outskirts of academic research, but in the recent years, particularly through the publication of the critical edition of Steiner's works (Steiner 2013), it has attracted increasing attention. Current research is often mainly historical, focusing on the cultural and social context in which Anthroposophy developed (Schmidt 2010; Staudenmeier 2014; Zander 2007), but there are also examples of Steiner's work now being considered for instance in philosophy (Schickler 2005; Traub 2011; Sparby 2016) and psychology (Weger and Edelhäuser 2014). No studies have up until now focused on actual experiences related to Anthroposophic meditation and spiritual practice. To fill this gap and open up potential new avenues of research, the project that led to this article was undertaken. The main guiding research question of the project was: What are the actual experiences of people undertaking Anthroposophic meditation and spiritual practice? Since there have been no studies on this previously, an explorative qualitative methodology was chosen, the details of which are presented below. Many different aspects of the actual practice of 30 practitioners of Anthroposophic meditation were explored. This article focuses specifically on the perceived effects of the two most common practices found in the present sample. Further work, including an overview of the whole range of experiences connected to Anthroposophic meditation, is in progress. This introduction describes the background of the issues relating to the present article and gives an outline of Anthroposophic meditation practice, in particular the traditional view of Anthroposophic mantra practice and subsidiary exercises Section 1 . This is followed by a methods 
Section 2, and a section for presenting results Section 3. There is then a discussion Section 4, followed by a brief consideration of limitations and future studies Section 5, and a conclusion Section 6.

\subsection{Background}

It is an open question whether it is possible to discern the basic features of meditation and to describe them in terms that are not tied to a specific tradition. An approach looking for such features might, for instance, try to describe meditation in neutral, secular or, phenomenologically grounded terms, or in terms drawn from established scientific knowledge of the human organism (Lutz et al. 2015; Nash and Newberg 2013; Sparby 2018a). Indeed, it may be doubted whether such an ideal is realizable at all. Is it possible to transcend one's cultural embeddedness when undertaking such an endeavor? Though researchers have tended to answer this question in the negative over the last decades, the tide may be shifting as indicated by a handful of recent publications (Flood 2015; Rose 2016; Sarbarcker 2006; Taves 2011). In order to move forwards it is in any case necessary to thoroughly investigate a wide variety of different meditative practices, traditions, and communities. This may not only reveal potential universal features of the meditative activity, but also make us more sensitive to how the meditative traditions and potential effects of meditation that we chose to focus on is a reflection of our own perspective and background.

Current meditation research is predominantly focused on Buddhist forms of meditation, or other forms of meditation, such as mindfulness meditation (Eberth and Sedlmeier 2012), which have a strong Buddhist influence (Kabat-Zinn 2011). In general, the effects that are investigated relate to physical and mental health, as well as attention and emotion, rather than the potential increase of insight or wisdom and how this might impact daily life. A reason for this might be that there currently are no intersubjective standards for measuring the increase of spiritual wisdom and its application. The present study investigates Anthroposophic meditation in an attempt to widen the scope of meditation research to include such issues. This is not only a matter of meditation research becoming more comprehensive, and thereby more scientific (Sparby 2017b), but also a matter of investigating further aspects of meditative activity that may lead to different results than those coming out of the Buddhist tradition.

Anthroposophy, which was founded by Rudolf Steiner (1861-1925), is today most well-known through the various social initiatives that arose from it, such as Steiner/Waldorf schools and Anthroposophic medicine. Steiner also formulated a way of meditation which was intended to give rise to insights into the human being, the "higher self", and the world, for instance by meditating specific ideas or thoughts, while also inspiring social and cultural renewal. Furthermore, suffering, a central topic in many spiritual traditions, is in Anthroposophy often seen to contain a developmental potential; for Steiner, pain and suffering is part of a process through which one learns to overcome egotism (Steiner 1991, GA 110, pp. 182-83, 2000, GA 227, pp. 56-57) and gains knowledge of a higher reality (Steiner 1999, GA 231, pp. 47-48). This is a complex topic, but the general idea is that true knowledge is gained by connecting to something greater than oneself, which implies dismantling the ego. As such, Anthroposophy provides meditations and frameworks of understanding that are aligned with traditional European ideals such as seeking to understand the world intellectually for its own sake (Lear 1988), emphasizing the positive value of the individual self (Taylor 2012) and investigating nature, the cosmos and the human being in order to improve human life, culture and society (Hegel 1991). In the West suffering is sometimes given a positive significance, as exemplified by notions such as catharsis in antiquity and atonement in Christianity; even death is sometimes viewed in a positive light, as in the Goethean expression "stirb und werde!" This is opposed not only to many contemporary ways of framing meditation practice, but also to traditional Buddhist practice, in which ultimate insight is contingent upon diminishing the activity of discursive cognizing (Brown 2006). In the Buddhist tradition, insight into the particular nature of phenomena and natural kinds (beyond general characteristics such as impermanence) is generally not pursued (Sparby 2015). Meditation is conceived of as a way of seeing through the illusion of the individual self (Ryan and Rigby 2015), with 
the ultimate aim of moksha or liberation from the suffering of cyclic existence within the illusory world of samsara (Williams et al. 2012). Indeed, enlightenment, liberation or awakening can be conceived of as the conjunction of the idea of insight into true realty and the end of suffering (Williams 2004). However, there are Buddhist practices that utilize suffering as part of meditation practice, such as for instance tonglen (Chödrön 2001) and mahamudra (Namgyal 2001). Hence, though Anthroposophy is not based on the idea of gaining insight with the aim of ending suffering and escaping cyclic existence, the finer points of the contrast between Anthroposophy and Buddhism is something that can indeed be worked out in more detail in order to understand both traditions better. In any case, Anthroposophy not only provides novel ways of understanding meditation practice that are generally lacking in current research on meditation, but might also provide a way of contextualizing meditation practice that is more in resonance with the Western mind and its ideals of scientific conduct, individualism, and a striving towards harmonization of this-worldliness and transcendence.

\subsection{Outline of Anthroposophic Mantra Practice and the Subsidiary Exercises}

This section gives an overview of the general aspects of Anthroposophic meditation practice (Section 1.2.1) and presents the traditional Anthroposophic understanding of mantra practice (Section 1.2.2) and the subsidiary exercises (Section 1.2.3).

\subsubsection{General Aspects of Anthroposophic Meditation Practice}

Anthroposophic meditation arose in a European cultural context around the beginning of the 20th century. In general, Anthroposophy is influenced by European philosophy, including German idealism, the work of Goethe, Friedrich Nietzsche, and naturalists like Ernst Haeckel, to name a few. The particular form of meditation it presents draws upon European esotericism and mysticism, but also on Theosophy, through which it receives some terms and ideas of an Asian origin. Though the text material of Steiner's works, consisting of around 350 books, can be daunting and perplexing, certain overall tendencies in his view of meditation can be gleaned (Sparby 2017a). The general aim of Anthroposophic meditation is to develop human cognition in such a way that it becomes disentangled from the physical body and becomes receptive to previously hidden, spiritual aspects of reality. Through a communion with the spiritual world that lies behind sensory reality, higher knowledge is sought, and this knowledge serves as a ground for reshaping different aspects of human culture, such as pedagogy, medicine, art, and science. This idea of "higher knowledge" may be compared to Plato's notion of noesis, Aristotle's idea of an active reason, different varieties of spiritual knowledge as presented in the Christian tradition, and ideas such as "intellectual intuition" in German idealism. In Asian traditions, we find similar ideas of "higher knowledge" represented by concepts such as prajna and the siddhis related to knowledge. This is not the place for giving an in-depth treatment of the varieties of higher knowledge within this tradition; suffice it to say that higher knowledge is not necessarily transcendent or irrelevant to human life in the self-understanding of Anthroposophic practitioners.

Many of the Anthroposophic meditations are quite simple and have the general goal of facilitating the process of gaining higher knowledge. However, there are also a set of practices that specifically target the development of "organs of higher perception" of the human being (Steiner 1992). As described elsewhere (Sparby 2017a), the autonomy of the practitioner is central, the importance of having a teacher is downplayed, and the development of the practitioner's moral character is seen as essential. Little attention is given to having a specific environment for practice and having the right posture. The duration of practice typically recommended is ca. $10-30 \mathrm{~min}$ and the general attitude is anti-monastic, i.e., the practitioner is not advised to go on retreats or separate themselves from ordinary human life. Though a great variety of meditations can be found in Anthroposophy, a structure of practice commonly found in Steiner's works includes one phase of concentration or focused attention followed by a period of open presence. The latter phase is intended to reveal the deeper nature or 
spiritual aspect of the meditation object, which can then become a new object of focus (Wagemann 2011; Zajonc 2009; Steiner 1992).

\subsubsection{Mantra Practice}

Anthroposophic mantra practice usually consist of either one sentence or a series of sentences (some up to 50 lines or longer), and mantras can be vocalized or meditated upon in silence. Sometimes single words are taken as a meditation object. The mantras resemble poems in that they make use of rhythm and the sound of words to evoke thoughts and emotions. Mantras also do not represent any factual circumstances, though they may employ imagery such as light, depth, and beings, both human and divine. The actual process of meditating mantras can to a certain extent be determined by the practitioner. Typically it is suggested that the focus should be on making the content of the words "come alive", i.e., that they become phenomenologically rich and intense. It is also possible to take the sounds and rhythms of the mantra as an object of focus. In addition, when meditating words like "light" one can also take imagination of light as an object of focus. No emphasis is put on a continual repetition of the mantra; rather it is suggested that one repeats the mantra in order to refresh the meaning. As with Anthroposophic meditation in general, the aim of mantra meditation is to connect or open up to the spiritual world (Steiner 2008, GA 270c, p. 23, 1995, GA 266a, p. 285); mantras are said to strengthen consciousness and focus its energy into creating new organs of perception so that the beings and facts of the spiritual world become knowable (Steiner 1987, GA 17, pp. 12-13). The vocals, consonants, and rhythms of the mantras are believed to be of importance, as there is a correspondence between them and certain laws of the spiritual world (Steiner 1995, GA 266a, p. 286). This also means that the mantras are particularly difficult to translate (Steiner 1995, GA 266a, p. 197).

\subsubsection{Subsidiary Exercises}

The subsidiary practices (often referred to as "Nebenübungen") are the second most common form of practice undertaken by the participants of this study. The most well-known variety of this practice is described in Steiner's Die Geheimwissenschaft im Umriss (Steiner 1989). The subsidiary exercises have the function of stabilizing, securing, and balancing the thoughts, emotions, and moral character of the practitioner, while also strengthening and supporting the second or "higher self" that will develop in the course of the meditative practice (Steiner 1989, GA 13, pp. 329-30, 1995, GA 266a, p. 406, 1996, GA 266b, p. 347, 2001, GA 267, p. 62). In other words, the subsidiary exercises are thought to counterbalance potential meditation-related challenges. It may also be noted that the subsidiary exercises are thought by Steiner and Anthroposophic practitioners to awaken the heart chakra (Lowndes 2000), which suggest that these exercises can be seen to constitute a central part of Anthroposophic meditation practice, since it generally aims at awakening the chakras (Steiner 1992).

There are six subsidiary exercises, and Steiner's descriptions of the exercises vary to a certain extent. The following description is based on the instructions found in Geheimwissenschaft im Umriss. Strictly speaking, only the first exercise constitutes a form of meditation, in that it involves focusing one's thoughts on a specific object for a certain amount of time. The object does not have to be particularly interesting or profound; the important point is that one thinks in a matter-of-fact way about the object. Typical questions one would ask oneself are: "Which materials were used to create the object? Where do these materials come from? When were objects of this kind invented?" The second practice consists of choosing one simple act to repeat every day at the same point in time. It should be an action that one would normally not do and that has no immediate practical value, the intention being to train the will. An example would be taking off a ring one carries and putting it back on. The third practice consists of developing equanimity; one should learn to control the expression of desire and joy, suffering and pain. Whenever one notices an emotional overreaction one takes care to regulate the expression. However, this does not mean that one should repress feelings and emotions, but rather halt their involuntary expression, which should also lead to a more intensified experience of joy and pain while at the same time increasing equanimity. The fourth exercise is focused on 
developing positivity. The experience of negative properties, such as falsehood, evil, and ugliness, should not stop the practitioner from looking for truth, goodness and beauty. The practice consists of looking for such positive properties in daily life situations. The fifth exercise involves developing the virtues of openness or impartiality through seeing from different perspectives and bracketing one's prejudices. However, the practitioner should always be ready to balance knowledge gained through previous experiences with being receptive to new experience. The final exercise seeks to bring harmony between the different capacities and virtues that are developed, through, for instance, practicing the exercises in different combinations. A parallel to the subsidiary exercises may be found for instance in the Buddhist practice of the brahmaviharas, the four divine abodes or four immeasurable, consisting cultivating loving-kindness, compassion, sympathetic joy, and equanimity.

\section{Method and Participants}

The following gives an overview of the method used in this project. A more in-depth description is available elsewhere (Sparby 2018b). Since the effects of Anthroposophic meditation have not been investigated previously, a qualitative methodology was chosen which is well suited to exploring new areas of enquiry (Given 2008; Tewksbury 2015; Velmans 2000). The methodology was inspired by the Varieties of Contemplative Experience project (VCE) (Lindahl et al. 2017) and the principal investigator (hereafter "P.I.") received initial training from members of the VCE team. However, this study was conducted independently of VCE. Since this is an exploratory study, the aim is not to test a specific hypothesis, but gain an understanding of the potential effects of Anthroposophic mediation practice in a way that can guide future operationalizations of these effects.

Participants were recruited through purposive sampling (Tashakkori and Teddlie 2010), snowball sampling (Faugier and Sargeant 1997), and special case sampling, (Teddlie and Yu 2007). The main aim was to find practitioners who could report on a large range of experiences and the P.I approached practitioners who were already known to him. These practitioners suggested further participants, and the P.I. contacted potential candidates with either significant or unexpected experiences, all of European origin. For the demographics of the participants, see Table 1.

Table 1. Participants' demographics.

\begin{tabular}{c|c}
\hline \multicolumn{2}{c}{ Demographic Characteristics } \\
\hline Female (\%) & $9(30 \%)$ \\
\hline Male (\%) & $21(70 \%)$ \\
\hline Mean age (years) & 51 \\
\hline Average duration of regular practice (years) & ca. 21 (range: 1.5-41) \\
\hline European nationalities (\%) & $\begin{array}{c}\text { German: 14 (47\%), Norwegian: 6 (20\%), Swiss: 3 } \\
(10 \%), \text { British: 2 (7\%), Belgian: 1 (3\%), French: 1 (3\%), } \\
\text { Austrian: 1 (3\%), Russian: 1 (3\%), Danish: 1 (3\%) }\end{array}$ \\
$\begin{array}{c}\text { At least one parent: } \\
\text { Anthroposophic: 6 (20\%) } \\
\text { Catholic: } 9(30 \%)\end{array}$ \\
Evangelical: 13 (43\%) \\
\hline
\end{tabular}

Some of the experiences that were described had happened many years in the past. This had the drawback that some descriptions were less detailed in comparison to the descriptions of more recent examples. However, that such distant experiences were remembered indicate that they not only have been significant to the participants, but also that they may be representative of what is remains central to someone who has practiced Anthroposophic meditation for many years. In other words, the aim of this study was not to gain a rich description of a small set of specific perceived effects but to develop a broad overview of the range of potential effects. Hence neither the relative nor absolute percentage of 
perceived effects have been stated; given that the number of participants and method of recruitment any statistical relevance can in any case not be derived.

The study design was approved by the ethics commission at the University of Giessen and 30 semi-structured interviews were conducted by the P.I. Participants were encouraged to avoid traditional terms and rather describe their experiences phenomenologically. The interviews took place from 2014-2015. The interviews were analyzed by the P.I. following a procedure of inductive or exploratory thematic analysis (Guest et al. 2012). The themes identified were reviewed by the research team at the University of Giessen and a research assistant. After this, initial definitions of the themes were developed and the transcripts were reviewed again with the definitions in view, which led to a refinement of some of the definitions and revisions of which text passages were identified as representing a theme. This process, which was as assisted by software for qualitative analysis (MAXQDA), was iterated until no further refinements were deemed necessary. The resulting overarching themes will be the main focus of another article. The present article is focused on descriptions of perceived effects connected to mantra meditation and the subsidiary exercises (though sometimes includes other themes insofar as they are relevant to understanding how the perceived effects are interpreted by the practitioners). The different descriptions of the perceived effects were compared and summarized.

The P.I. was a post-doctoral researcher when the study was conducted and has previous in-depth knowledge of Anthroposophy based on academic studies and personal interest, and practices different forms of meditation, including meditations coming from the Anthroposophic, Buddhist and other traditions. The objection that the P.I. is biased may therefore be close at hand. Any views that the P.I. may have about the truth value of Anthroposophic, Buddhist or other beliefs were bracketed so far as possible while conducting the interviews and performing the analysis. However, unconscious or pre-reflective views cannot, and perhaps should not, be completely inactivated. The notion that research can or should be undertaken in an interpretative vacuum is misguided. Everyone approaching to a research topic will bring with them specific interests and research ideas. This may be vital for making new discoveries. Furthermore, a previous understanding of a somewhat closed conceptual system or worldview, like Anthroposophy, may also be an advantage when interpreting and presenting research findings to others.

Given that Anthroposophic practice has an uncommon framework of reference, certain reports can be difficult to understand. A compromise had to be struck between the emic and etic perspective, i.e., between presenting the reports in a way that remains true to the Anthroposophic framework and making the reports understandable in common terms. During the interviews the participants were encouraged to use experiential terms rather than traditional ones in order make the reports more understandable, but this was not always possible. Short explanations or synonyms have been used in cases where traditional terms are used. For example, "incarnation" refers to a form of embodiment, whereas "excarnation" means the opposite, i.e., a process or state of disembodiment or an out-of-body experience.

\section{Results}

$26(87 \%)$ of the participants of the current sample practiced or had practiced mantra meditation while $25(83 \%)$ practiced the subsidiary exercises in addition to other meditations. In contrast, two other popular Anthroposophic practices, the rosy cross meditation and the daily review were both practiced or had been practiced by only $14(47 \%)$. Of the mantras, the most popular one's were the so-called "Klassenmantras" (14 (47\%)), the Foundation Stone Meditation ("Grundstein") (10 (33\%)), and "it thinks, she feels, he wills" ("es denkt, sie fühlt, er will") $(9(30 \%))$. Note that the mantras are mostly meditated in the original language that they were given in, i.e. German. Table 2 below presents an overview of the reported perceived effects. These perceived effects are described in more depth in the next Section 3.1 describes the perceived effects of the mantra practice and Section 3.2 describes the perceived effects of the subsidiary exercises. 
Table 2. Perceived effects of Anthroposophic mantra practice and the subsidiary exercises.

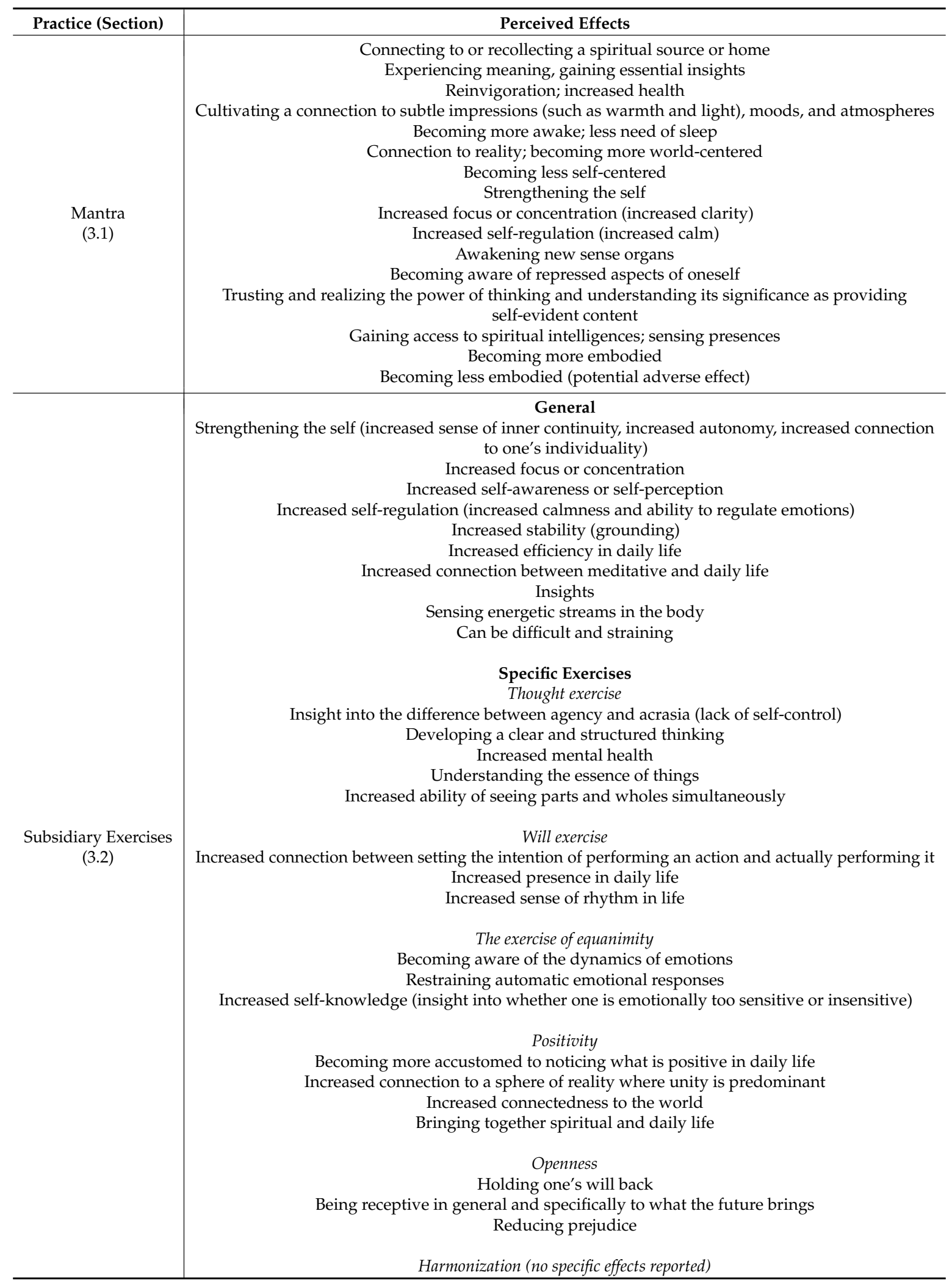

\subsection{Mantra Practice}

As mentioned in the introduction, a general aim of Anthroposophic mantra meditation is to establish a connection to a "spiritual world", i.e., a world that explains the origin of the human 
cosmos and to a certain extent what happens within it. The "spiritual world" corresponds to the divine or original realms of existence found in the different world religions. In Anthroposophy, the spiritual or divine realm is, however, not transcendent, but it is often not obviously present to human consciousness. The human being is also understood to have a divine core that is already part of the spiritual world. Meditation and other spiritual practices hence have the aim of enabling and supporting a widening of consciousness to include both the divine aspect of reality and oneself. This is described as an aim by the participants of this study. As one subject states:

"In the meditation itself, how should I put it, it is about becoming familiar with something, or remembering something that one knows, but has forgotten. Like a home, or like [ ... ] growing roots inside something deeply familiar that even my diary didn't know of anymore, or remembered."

It is indicated that working with the mantra implies recollecting a part of reality that one knows and is close to, but that one is also normally unaware of; a part of reality that is even more intimate than the personal reflections that are revealed in one's diary. And a "home" is something that belongs to external reality, but an external reality where one can immediately find oneself.

The participants reported different ways of working with the mantras: It can be about "condensing" the meaning of the mantra, experiencing qualities and moods, and moving through series of events, ideas, and emotions that are dynamic in a way that is similar to a drama. Some participants also reported working with the contrast of actively meditating the mantra and then going into a state of open awareness or empty consciousness while trying to become aware of the effects the mantra has. Here is a representative example of someone reporting on doing a mantra meditation:

"I also have experiences of meaning with words or sentences from mantras, where something is built up inwardly, and there is a response to that. And that which responds has the character of a being. [ ... ] I find that it is a strongly invigorating. There is a mantra by Steiner, which I've used repeatedly for a long time. [ ... ]. "In the pure rays of the light". But I don't do it for ten minutes, it's more of a tapping into it. But I notice that through invoking it daily, that this indeed brings me in touch with the warmth of the light, this light warmth [ ... ]. Connecting oneself to the light of the world and this warmth of the world, that brings strength. [... ] the strength that arises from this meaningful world, and through that I connect with it, something happens, I stand here changed. I'm connected in a different way. It always has to do with this sphere of meaning. When I get up after [having meditated the mantra] "In the pure rays of the light" [ ... ], then I'm somehow more clear, strengthened, more calm, I even have the impression of being more healthy, more awake and rested, as if I'm well-incarnated, but, so to speak, more incarnated in reality, not so much in the personal."

It is described here how even a short mantra meditation can bring about a sense of connection with the warmth and light of the world, that this brings with it perceived effects of feeling more clear, strengthened, calm, healthy, and so on. And, in particular, one becomes more embodied (or "incarnated"; see below for a further explanation of this term) within the world rather than within that which belongs to the ego-centered personality. Hence the mantra meditation shifts the focus from being self-centered to being more world-centered.

Similar effects are noted by other participants. These range from general perceived effects such as a strengthening of the self, increase in power of concentration, self-regulation and wakefulness, to particular perceived effects connected to specific mantras. Examples here are: Awakening new perceptual organs and approaching repressed (shadow) aspects of the self. Some mantras, such as "I can understand thinking through itself", focus on the meaning and significance of the thought process. Working with such mantras, participants mention a growing trust in thinking, experiencing how thinking fully discloses its own meaning, that its content is self-evident, and that there is nothing in the thought process itself that implies that it is determined by material processes. One further 
characteristic example is of one participant using a sentence taken from the works of Friedrich Theodor Vischer: "The soul, as the overarching unity of all processes, can indeed not be located in the body, although it is not anywhere else than in the body [translation by the author]." (Vischer 1889, p. 194). Here the mantra has a clear, though perhaps paradoxical, cognitive content.

Some participants also mention that certain mantras lead to insight into the workings of spiritual intelligences or beings that constitute the underlying fabric of reality (Steiner 1989; Pseudo-Dionysius 1987; Wiebe 2015). A further participant states that the basic phenomenological component of the experience of such beings is sensing the presence of a consciousness different to one's own. However, such a different consciousness does not necessarily exhibit personality. The same participant compares this to how one may sense a presence of "fish consciousness" when standing in front of an aquarium without at the same time sensing that each fish has a different personality.

There is one domain of experiences relating to mantra practice where there are conflicting reports. This is the domain of (in Anthroposophic terminology) incarnation and excarnation, which could also be referred to as the domain of embodiment and disembodiment or out-of-body experiences (OBEs). As already indicated, some participants refer to the mantra meditation as having a strengthening, embodying effect: "[Mantra meditation] leads to a strengthening of the different parts of myself, enables me to stand firmly on the ground, by myself, with more structure." And then we can refer to the longer quote above again: "Somehow I'm more clear, strengthened, calmer, more healthy." Two participants report on experiences with mantra meditation that are opposed to this. One of these participants describes a fearful OBE that happened when they first tried a mantra meditation. The experience was so intense and scary that it lead to her stopping meditation for a number of years. The second participant reported becoming dizzy and becoming less grounded (described as "loosening" ("Lockerung") as the result of mantra practice. This will be considered later in the discussion.

\subsection{The Subsidiary Exercises}

The strengthening of the self is highlighted as a general effect of the subsidiary exercise by three participants of this study. One aspect of this is the protection against a fragmentation of the self that is connected to deep spiritual practice:

"And I believe that is completely essential, because during meditation one can experience that one indeed crosses the threshold to the spiritual world. But when one comes back, one can experience a kind of fragmentation of consciousness. If you have developed a strong I-consciousness, this is something that prevents fragmentation. So having a strong I-consciousness is essential. Therefore I'm also critical towards many of these spiritual movements that talk about killing the ego. That one should ... that the ego is viewed as something negative. The ego should not be removed, it should not be crushed, it should not be killed, it should be developed. That is very essential to me. And it potentially counteracts mental illnesses, so an I-consciousness is terribly important."

As described earlier, the mantra meditation has the aim of bringing the practitioner into contact with a spiritual world. Some dangers are said to be involved in this, as indicated earlier, and the subsidiary practices help to counteract this. The strengthening of the self, however, manifests in different ways through the practices; this will become clearer as we proceed through the reports about the perceived effects of the different practices. Some practitioners mention general perceived effects such as an increase in focus, the ability of self-awareness or self-perception and the arising of insights. Different forms of self-regulation effects are also perceived, such as increased calmness, emotional stability or emotional hygiene. The practice is also in general described as grounding and that taking care of daily life becomes easier or that a connection between one's spiritual/meditative life and one's regular life is established. One participant mentions that insight into past lives has arisen through the practice and that also certain sensations of energetic streams are felt in the body. No perceived 
adverse effects are mentioned in connection with the subsidiary exercises, but the practice is sometimes described as difficult and straining. Two participants stated not noticing any particular effects.

The first exercise, the thought exercise, was reported as leading to noticing the difference between actually controlling one's thoughts and the inability of doing so, or in other words noticing the difference between agency and acrasia. Developing clear and structured thinking is also mentioned, which is also seen to be connected indirectly to developing a more structured, clear, and healthy mental life. Two participants also noticed developing the ability of understanding the essence of things, of seeing the parts of a whole simultaneously.

The second exercise, which is the exercise of the will, is generally perceived as being difficult, at least initially. One participant describes a shift from the early stage of practice, where one has to struggle with remembering to do an action at a specific time, to a stage where it comes by itself. Another practitioner describes what is in a sense an intermediary stage where one discovers a real condition for doing the practice successfully: "[T]here's one way that [ . . . I can do that exercise consistently, and that is if I really take a whole day up until I do that [ . . ] as a kind of presence exercise. In other words, [ . . ] ] I have to hold it through the whole day." Here the key is to not simply trust that one will remember to do the action at the set point in time, but rather to have the task in peripheral awareness and bring it to mind repeatedly throughout the day.

One participant underlines that the third exercise, the practice of equanimity, is about finding a golden middle between having too strong and too weak emotional reactions. The exercise is concerned with becoming aware of how the world of emotions works and developing the ability to restrain automatic emotional reactions. Finding out for oneself how to deal with this exercise is also important for some. One participant report being quite equanimous already, while another struggled with this exercise in particular. Hence, besides finding out how exactly to do the exercise, it involves working out a balance for oneself, developing the trait of equanimity to the extent that one needs it.

The practice of positivity and openness are connected by two participants in similar ways. As one participant states:

"For example, in relation to the practice of positivity one initially has to make a terrible effort to find something positive. And with time one notices that it has become like a need to not only look at the negative, but at something positive as well. Our daily life is characterized by negative judgments, and that encapsulates you, leads to separateness. The sphere where you generally also ask for the positive is like another sphere. Because positivity does not lead to separateness. Rather positivity, like openness, leads to an inner connection. Below this is that which separates, and above is a layer of positivity and openness, and one notices that that is a reality which exists. One latches on to this through the practice. It doesn't always work for me. And still, life totally changes, when it does work to anchor oneself and stay in this sphere."

\section{And another participant states:}

"Positivity, right. And openness ... to me both of those are great experiences. [ ... ] because that is exactly what I have sought, really, I think, this access to the world [ ... ] as if one merges with the world. One has the feeling, I merge [with the world], and at the same time I have a spiritual practice, without having the sense of somehow standing on the outside [of the concerns of the world]. The fifth is impartiality, yes, it is also somewhat similar to the practice of positivity, and both of these are [ ... ] very important to me. Positivity is more about finding the good, [ ... that which is bad [ ... ] one sees anyway [ ... ]. In relation to impartiality one makes an attempt at openness, let's say, [one tries] to hold one's will back, and embrace that which comes from the future, that which comes towards you, to approach it without prejudice. So there is an interconnection between the two practices."

The practice of the virtues of equanimity, positivity, and openness are all related to emotional development in particular. This form of practice can be seen as part of the process that is indicated 
here, where one connects to a higher reality through practicing equanimity, positivity and openness, but in a way that brings one closer to the world rather than further away from it.

Only two participants report on the harmonization exercise, one stating that they have not practiced this much, either because the exercise is itself difficult or because the other subsidiary exercises provide enough of a struggle in themselves. Struggling with figuring out how to do the practice can, however, be seen as part of the practice itself. Steiner even states that the instructions should not be too detailed, or else that would be too much of a potential intrusion into the autonomy of the practitioner (Steiner 2001, GA 267, p. 514). The practice is supposed to enliven the self, not make it dependent on a teacher, as is generally underlined in Anthroposophic practice (Sparby 2017a).

The theme of autonomy can be found throughout the interviews as well, and connects to the overarching notion of strengthening the self that is seen as a main function of the subsidiary exercises. One participant sees this overarching aim as reflected in the different practices:

"The subsidiary exercises, yes ... yes, there are more of them, right, but the fruits of the subsidiary exercises ... it really isn't the exercise itself that is important, what is important is the capacities of the soul that it develops. And what the subsidiary exercises do, which I believe might be Steiner's intention with them, is to strengthen yourself. It strengthens concentration, it strengthens the sense of rhythm in life, because you are supposed to for example chose to take off your ring at a certain point of time during the day [ ... ], it strengthens a kind of inner continuity. And, if there is something that maintains an inner continuity, then it is the self. My emotional life is unstable. It changes from hour to hour. Or from one day to another. Right? [ ... ] I can change my belief system, from one system to another belief system. I can, yes, there are many things that can change. But this deep sense that I am I, that is constant. And when one connects to this inner sense, or inner experience, I should say, for it is also ... the I isn't only a feeling, you experience the I, and when you connect to it, a much stronger inner continuity arises, both in this life, and the lives to come. Because there is something that follows, through the whole of this life, something that will incarnate again in the next incarnation, and something that has incarnated before. So the subsidiary exercises are very central exactly when it comes to creating a connection, a strong connection to your own individuality."

This quote makes it easier to understand what is fundamentally connected to the notion of the self among Anthroposophic practitioners: Through practice the self takes conscious control over certain mental capacities, such as concentration and will. The self is also represented by the constant sense that "I am I", an identity underlying emotional turbulence and changes of opinion. Through practice the self becomes aware of itself as this continuity. And it is conceived as a continuity or identity that goes beyond a single incarnation. The subsidiary practices create a connection to this continuity, thereby "strengthening" the self.

\section{Discussion}

To my knowledge this is the first study of the actual procedure and perceived effects of Anthroposophic meditation. This form of meditation presents a unique perspective on the significance of spiritual practice, in that it emphasizes cognition (both intellectual and higher) is centered on the development of the self, and that it strives to unite deep meditative practice with improving society and human culture in general. It can be noted that such a striving has also been part of Buddhism in the West, focusing on issues ranging from peace and environmentalism to mental health (Queen 2000). It may be the case that the Western emphasis on immanence inspires Western practitioners to focus on such issues, leading to the development of for instance Anthroposophic medicine and Steiner/Waldorf pedagogy.

Two forms of Anthroposophic practice have been presented here. Both practices are seen as different ways of strengthening the self (rather than dissolving it). It can be noticed that the higher 
spiritual aims of Anthroposophic meditation (such as developing new organs of perception) play a minor role in the accounts of the present sample. In contrast, different perceived effects relating to developing different aspects of the human being, including self-regulation and health, the connection between daily life and the meditative life of the practitioner, are central. There also appear to be two conflicting accounts of the perceived effects of mantra meditation: It leads both to being less self-centered and to a strengthening the self (point 7 and 8 of the mantra section of Table 2) and it apparently leads both to embodiment and disembodiment (point 15 and 16 of the same table). These issues, in addition to the potential the subsidiary exercises have as a means of avoiding adverse effects of meditation, will be discussed below. It may be noted that many of the descriptions of the participants resemble Steiner's description of what the effects of these practices should be. One could interpret this either to mean that the practices indeed have these effects or that the reports are confabulations in the sense that practitioners report, without any intention to mislead, effects that they have not really experienced, but rather what one should experience according to Steiner or other Anthroposophists. It is not possible to decide which interpretation is correct based on the current material-and both interpretations could be true to some extent. Further studies involving other methods will be necessary to untangle this.

As stated in the introduction, on traditional accounts, and also in the eyes of the participants of this study, Anthroposophic meditation seeks to initiate and support the development of organs of spiritual perception. Only on rare occasions have the participants been able to report on this aspect of Anthroposophic meditation practice. This is perhaps linked to the fact that teachers within the Anthroposophic community typically do not offer systematic training of the spiritual organs, which would involve guiding practitioners through a process of initiation leading up to a meeting with the so-called "higher self" (Steiner 1992). Most practitioners mainly meditate alone, working with books as the main source of instruction. Indeed, the tension between the potential of "higher knowledge", which is the most prominent form of motivation in the present sample (Sparby 2018b), and general lack of realization of this potential, is one of the most characteristic themes emerging from the interviews. Some participants describe confusion or frustration with the apparent lack of results coming from their meditation practice. Recently, there has been a discussion within the Anthroposophic community about what counts as higher knowledge (Tücher 2018). Some practitioners are seen as too liberal in their approach; misinterpreting basic traditional terms, they are perceived as having lowered the bar for what counts as such knowledge or completely misrepresenting it. In the Anthroposophic community it is also potentially problematic to present one's experiences as examples of higher knowledge as doing so may lead to becoming ostracized. Hence it is understandable that a lot may be at stake in relation to the issue of whether someone has attained valid "higher knowledge". Dissatisfaction with the results of one's practice may be a potential reason for why someone would want to lower the standard for what counts as higher knowledge, but it is also clear that Steiner's work describes different levels of realization, which could potentially resolve this problem (Sparby 2017c). In any case, the interviews contain little information on how the higher aims of Anthroposophic practice are achieved and how the lives of practitioners with a high degree of realization (in the traditional sense) are affected. In meditation research more generally, there are few detailed accounts available of how such advanced stages of practice are actually experienced. There are different reasons for this, including that the scientific study of meditation has yet to approach meditation and spiritual practice in a way where such practice is investigated according to its own self-stated aims. However, there are a few cases among the Anthroposophic practitioners that could be analyses more in-depth to potentially gain more clarity, and such cases are indeed starting to become part of the research on Buddhist meditation (Ataria et al. 2015; Hagerty et al. 2013).

One participant mentioned working on a mantra with a cognitive content: "The soul, as the overarching unity of all processes, can indeed not be located in the body, although it is not anywhere else than in the body." This sentence, which may seem paradoxical and therefore related to more well-known forms of koan meditation (Grenard 2008), has the purpose of opening up one's 
understanding to a form of existence that is not located in space at all (Steiner 1983, GA 21, p. 77). Meditating in this way can be compared to a combination of philosophical reflection and introspective research (Weger and Wagemann 2015), and is primarily directed towards gaining insight. In other words, though the practice of Anthroposophic meditation can potentially lead to philosophical or introspective insight, the realization of the aim of developing organs of higher spiritual perception may be rare. It is also clear that, according to the traditional Anthroposophic view, higher perceptions will start out as impressions with a low degree of intensity before gradually growing into perceptions that are stronger than physical perceptions (Steiner 1989). Though the unfolding of such a process is not documented by the interviews, with a few possible exceptions, statements such as that Anthroposophic meditation is like "growing roots inside something deeply familiar" point to the significance that this form of mediation may have for practitioners. That one can grow roots inside something familiar could be interpreted along the lines of a process epitomized by the Nietzschean imperative to "become who you are": There is a separation between the person one is at the temporal level and the form of underlying, true reality, and meditation practice makes it possible to increase the connection between these two.

In general, Anthroposophic meditation practice contains a certain set of preliminaries and conditions. These include textual study, working on one's character, and developing and refining the capacities of thinking, feeling, and will. Meditative practices are a continuation of these preliminaries and the line between meditation and non-meditative mental practice can at times be vague. Anthroposophic meditation also emphasizes the connection between the spiritual and daily life of the practitioner. This is in accordance with the general rejection of monasticism in Anthroposophy. The subsidiary exercises in particular enable meditative skills, such as concentration, awareness and the ability to regulate and cultivate emotions to be used within a daily life setting. The connection between a "higher" spiritual world and a "lower" world of human concerns can be understood as approaching the world with an attitude of positivity, openness, and equanimity rather than negativity, closed-mindedness and reactivity. The emphasis on connecting the spiritual world and human world in this way may be seen as characteristic of Anthroposophy, and clearly differs from spiritual outlooks which seek liberation from the human world.

The apparent conflict between strengthening the self and reducing self-centeredness can be resolved by viewing a strong self as one that does not need to maintain itself in opposition to others, but can enter into constructive relationships that are viewed as expanding the self rather than limiting it. However, there is potentially a undesired effect that is both mentioned by Steiner and by the participants, which consists of an increase of egotism, vanity, and arrogance as a result of spiritual practice. Some participants mention an increase in the sense of feeling that one is better than others through undertaking spiritual practice, which is also mentioned in Steiner's works (Steiner 1996, GA 266b, p. 297). This is a complex issue that we cannot pursue further here, but it can be noted that in some cases spiritual practice increases rather than decreases self-centeredness. This may indeed be connected to the aim of strengthening the self. However, although the self that is supposed to be strengthened is not the self-centered ego (Sparby 2016), it may, in practice, be difficult to separate the "lower" from the "higher self".

Now we turn to the issue of the conflicting accounts of the perceived effects of mantra meditation. I suggest that these different accounts can be reconciled by looking at the context surrounding the mantra practice and the Anthroposophic framework of understanding of incarnation and excarnation that informs the way the Anthroposophic meditators understand their practice. Anthroposophy presents a view where the soul is relatively independent of the physical body; as a child develops, a process of incarnation takes place, which is expressed through the development of intelligence, self-awareness, social skills, and so on. As it develops, the physical body is seen to become a vehicle that can adequately facilitate and express the soul. This could be called the positive side of incarnation. There is also a negative side of incarnation in the Anthroposophic view which is represented by too strong attachment to the material world, in the sense of exclusive focus on the satisfaction of desires 
through material means and identifying with one's physical body (as opposed to being concerned for instance with ideas, stories, building character, and so on).

There is also a positive and negative side to excarnation. The positive aspect relates to everything that can be designated as "higher" in the human being: Realizing truth and non-material bliss, developing a unity with the cosmos, finding one's true identity, returning to one's origin or home (Steiner 1989, 1992). However, excarnation can also lead to the opposite: Detachment, losing one's identity, fear, becoming dreamy, untruthful, and narcissistic, entering into a liminal state or limbo, and so on (Steiner 1995, 1996, 1998b). Incarnation and excarnation are in themselves neither good nor bad. A healthy human being is seen as getting the balance right between the two; human life is characterized by a continual interaction between incarnation and excarnation. A similar polarity is found in the body in the processes of composition and decomposition. Consciousness is said, according to Steiner, to arise through the decomposition of the body (excarnation), a process that needs to be balanced by recomposition (incarnation) which happens during sleep (Steiner 1998a). Hence the process of life and death, consciousness and unconsciousness, are deeply interwoven. Through meditation the process of excarnation becomes conscious; an indication of this may be that one attains the so-called "continuity of consciousness" or remaining awake during the sleep state, which Steiner claims will happen as part of the meditative development (Steiner 1992). As the process of excarnation becomes conscious, the negative aspects of excarnation mentioned above become a real possibility: The soul is supposed to be strengthened through its physical life to such a degree that it can sustain a conscious, physically disembodied existence. If it is not strong enough, the result is a detached depersonalized human being that is also prone to fainting or having seizures, becoming dreamy and detached from human concerns, and mentally or even physically ill.

The participants who describe mantra meditation as having an incarnating effect could possibly refer to the positive aspects of incarnation is viewed to have in Anthroposophy, while the other participants refer to the negative aspects of excarnation. Whether there is a general agreement that mantra practice really should lead to either the positive effects of excarnation or incarnation (or both) cannot be answered by the material gathered.

One participant explicitly states that the subsidiary exercises have the effect of preventing mental illness that can result from spiritual practice. Many others stated that they stabilize and strengthen the self in the way described above. The issue of potential negative effects of meditation have increasingly been raised in recent research (Lindahl et al. 2017; Tremmel and Ott 2017). Steiner raises the issues of potential negative or challenging effects of meditation on many occasions, and there can be numerous reasons for this, for example that the practice has been unbalanced (Steiner 1992). Whether practicing the subsidiary exercises really has the effect of preventing adverse effects, i.e., effects that either lead to functional impairment in daily life or are contrary to the aims of the practice as stated in the traditional literature, cannot, however, be decided on the basis of the present sample.

Since there is a certain degree of overlap between the different accounts of the perceived effects of the practices considered here (mantra meditation and the subsidiary exercises) - both are for instance seen to strengthen the self-it can be asked whether the perceived effects are really due to the specific exercises or whether they come as a result of engaging in some form of mental practice. Doing any form of practice might be seen to have a beneficial effect in that the subject has to exercise self-discipline while attaching meaning to undertaking the spiritual practice and gaining a sense of mastery when the practice goes well. Such issues would need to be addressed by additional studies with larger samples.

\section{Limitations and Future Studies}

The clearest limitation of this study is the gender imbalance and that the participants are all of European origin. The aim of the study was to gather qualitative data on all aspects of Anthroposophic spiritual practice with a primary focus on meditation. As already indicated, this means that there is relatively little in-depth information available about the practice and effects of specific meditations. Furthermore, the accounts are based on experiences that sometimes lie many years in the past, which 
means that their accuracy may be questioned. Future studies with new samples may remedy this by having a group of meditators do the same practice for a set amount of time while taking notes as the practice unfolds, i.e., before, during, and after meditation. An additional important step would be to compare the effects of Anthroposophic practice to other types of meditation. Finally, it may be noted that the specific effects of specific mantras were not investigated; future studies may seek to investigate this further.

\section{Conclusions}

Anthroposophic meditation presents novel perspectives on the significance of meditative practice. It opens up a deep cognitive engagement in the meditative process, does not seek to dissolve but rather strengthen and develop the self, and advocates for the involvement of spiritual practice in all aspects of human life, including the social and cultural environment. By investigating two of the main Anthroposophic practices a range of different effects were uncovered that are summarized in Table 2. Some perceived effects overlap with findings from other studies, such as health-related effects. Others, such as self-regulation also partially overlap with typical findings in other studies of meditation. However, in Anthroposophic meditation, there is also a focus on actively engaging daily life for instance with an attitude not only of equanimity, but also of openness and positivity, and this is seen as part of the spiritual practice. Besides increasing a sense of having a spiritual home, there are also reports of perceived effects that go beyond what is currently being researched. This includes perceived effects such as connecting to a higher self, sensing energetic streams in the body, interacting with sensed presences, and gaining insight into past lives. Furthermore, a tension between striving for transcendence and increasing immanence (one's connection to the world) through meditation was also revealed. Additionally, the subsidiary exercises have been seen to stabilize the meditator and potentially lead to the prevention of adverse effects. More in-depth qualitative studies and quantitative studies with larger samples are needed in order to advance the research within this new field.

Funding: This research was funded by the Mind and Life Institute grant number 2014-Varela-Sparby, Vidarstiftelsen, Rudolf Steinerstiftelsen, Anthroposophische Gesellschaft in Deutschland, Software AG Stiftung.

Acknowledgments: Thanks to Jared Lindahl, Michael Tremmel, and Fergus Anderson, who all helped improve this article through their thoughtful comments and suggestions.

Conflicts of Interest: The author declares no conflict of interest.

\section{References}

Ataria, Yochai, Yair Dor-Ziderman, and Aviva Berkovich-Ohana. 2015. How Does It Feel to Lack a Sense of Boundaries? A Case Study of a Long-Term Mindfulness Meditator. Consciousness and Cognition 37: $133-47$. [CrossRef] [PubMed]

Brown, Daniel. 2006. Pointing Out the Great Way. The Stages of Meditation in the Mahamudra Tradition. Boston: Wisdom Publications.

Chödrön, Pema. 2001. Tonglen. The Path of Transformation. Halifax: Vajradatu Publications.

Eberth, Juliane, and Peter Sedlmeier. 2012. The Effects of Mindfulness Meditation: A Meta-Analysis. Mindfulness. [CrossRef]

Faugier, Jean, and Mary Sargeant. 1997. Sampling Hard to Reach Populations. Journal of Advanced Nursing 26: 790-97. [CrossRef] [PubMed]

Flood, Gavin. 2015. The Truth Within. A History of Inwardness in Christianity, Hinduism, and Buddhism. Oxford: Oxford University Press.

Given, Lisa M. 2008. The Sage Encyclopedia of Qualitative Research Methods. Los Angeles: The MIT Press. [CrossRef]

Grenard, Jerry. 2008. The Phenomenology of Koan Meditation in Zen Buddhism. Journal of Phenomenological Psychology 39: 151-88. [CrossRef]

Guest, Greg, Kathleen M. MacQueen, and Emily E. Namey. 2012. Applied Thematic Analysis. Los Angeles: SAGE. [CrossRef] 
Hagerty, Michael R., Julian Isaacs, Leigh Brasington, Larry Shupe, Eberhard E. Fetz, and Steven C. Cramer. 2013. Case Study of Ecstatic Meditation: FMRI and EEG Evidence of Self-Stimulating a Reward System. Neural Plasticity. [CrossRef] [PubMed]

Hegel, Georg Wilhelm Friedrich. 1991. The Encyclopaedia Logic: Part I of the Encyclopaedia of the Philosophical Sciences with the Zustze. Indianapolis: Hackett.

Kabat-Zinn, Jon. 2011. Some Reflections on the Origins of MBSR, Skillful Means, and the Trouble with Maps. Contemporary Buddhism 12: 281-306. [CrossRef]

Lear, Jonathan. 1988. Aristotle: The Desire to Understand. New York: Cambridge University Press.

Lindahl, Jared R., Nathan E. Fisher, David J. Cooper, Rochelle K. Rosen, and Willoughby B. Britton. 2017. The Varieties of Contemplative Experience: A Mixed-Methods Study of Meditation-Related Challenges in Western Buddhists. PLoS ONE 12. [CrossRef] [PubMed]

Lowndes, Florin. 2000. Enlivening the Chakra of the Heart: The Fundamental Spiritual Exercises of Rudolf Steiner. London: Sophia Books.

Lutz, Antoine, Amishi P. Jha, John D. Dunne, and Clifford D. Saron. 2015. Investigating the Phenomenological Matrix of Mindfulness-Related Practices from a Neurocognitive Perspective. American Psychologist 70: 632-58. [CrossRef] [PubMed]

Namgyal, Dakpo Tashi. 2001. Clarifying the Natural State. A Principal Guidance Manual for Mahamudra. Hong Kong: Rangjung Yeshe.

Nash, Jonathan D., and Andrew Newberg. 2013. Toward a Unifying Taxonomy and Definition for Meditation. Frontiers in Psychology 4. [CrossRef] [PubMed]

Pseudo-Dionysius, the Areopagite. 1987. Pseudo-Dionysius: The Complete Works. New York: Paulist Press.

Queen, Christipher S. 2000. Engaged Buddhism in the West. Boston: Wisdom Publications.

Rose, Kenneth. 2016. Yoga, Meditation, and Mysticism. London: Bloomsbury Academic.

Ryan, Richard M., and C. Scott Rigby. 2015. Did the Buddha Have a Self?: No-Self, Self, and Mindfulness in Buddhist Thought and Western Psychologies. In Handbook of Mindfulness: Theory, Research, and Practice. Edited by Kirk Warren Brown, J. David Creswell and Richard M. Ryan. New York: The Guilford Press, pp. 245-65.

Sarbarcker, Stuart Ray. 2006. Samadhi. The Numious and Cessative in Indotibetan Yoga. Albany: State University of New York Press.

Schickler, Jonael. 2005. Metaphysics as Christology. An Odyssey of the Self from Kant and Hegel to Steiner. Ashgate New Critical Thinking in Religion, Theology, and Biblical Studies. Aldershot: Ashgate.

Schmidt, Robin. 2010. Rudolf Steiner Und Die Anfänge Der Theosophie. Dornach: Rudolf Steiner Verlag.

Sparby, Terje. 2015. Investigating the Depths of Consciousness Through Meditation. Mind and Matter 13: $213-40$.

Sparby, Terje. 2016. Rudolf Steiner's Idea of Freedom: As Seen in the Panorama of Hegel's Dialectic. Epoché: A Journal for the History of Philosophy. Epoché: A Journal for the History of Philosophy 21: 173-95. [CrossRef]

Sparby, Terje. 2017a. Anthroposophical Meditation and Spirituality. Connecting Divinity and Nature through the Human Being. Studies in Spirituality 27: 195-218.

Sparby, Terje. 2017b. The Nature of Contemplative Science and Some Prospects for its Future Development. Journal of Consciousness Studies 21: 226-50.

Sparby, Terje. 2017c. Die Bereiche und Stufen der höheren Erkenntnis. Die Drei 12: 47-56.

Sparby, Terje. 2018a. A System of Classification of Anthroposophic Meditation. Complementary Medicine Research, under review.

Sparby, Terje. 2018b. A Qualitative Study if Motivations for Meditation in Anthroposophic Practitioners. PLOS $O N E$, under review.

Staudenmeier, Peter. 2014. Between Occultism and Nazism. Anthroposophy and the Politics of Race in the Fascist Era. Leiden: Brill.

Steiner, Rudolf. 1983. Von Seelenrätseln. Dornach: Rudolf Steiner Verlag, vol. GA 21.

Steiner, Rudolf. 1987. Die Schwelle Der Geistigen Welt. Dornach: Rudolf Steiner Verlag, vol. GA 17.

Steiner, Rudolf. 1989. Die Geheimwissenschaft Im Umriss. Dornach: Rudolf Steiner Verlag, vol. GA 13.

Steiner, Rudolf. 1991. Geistige Hierarchien Und Ihre Widerspiegelung in Der Physischen Welt. Dornach: Rudolf Steiner Verlag, vol. GA 110.

Steiner, Rudolf. 1992. Wie Erlangt Man Erkenntnisse der Höheren Welten? Dornach: Rudolf Steiner Verlag, vol. GA 10 . 
Steiner, Rudolf. 1995. Aus Den Inhalten Der Esoterischen Stunden I. Dornach: Rudolf Steiner Verlag, vol. GA 266a. Steiner, Rudolf. 1996. Aus Den Inhalten Der Esoterischen Stunden II. Dornach: Rudolf Steiner Verlag, vol. GA 266b. Steiner, Rudolf. 1998a. Anthroposophische Leitsätze. Dornach: Rudolf Steiner Verlag, vol. GA 26.

Steiner, Rudolf. 1998b. Aus Den Inhalten Der Esoterischen Stunden III. Dornach: Rudolf Steiner Verlag, vol. GA 266c. Steiner, Rudolf. 1999. Der Übersinnliche Mensch Anthroposophisch Erfasst. Dornach: Rudolf Steiner Verlag, vol. GA 231.

Steiner, Rudolf. 2000. Initiations-Erkenntnis. Dornach: Rudolf Steiner Verlag, vol. GA 227.

Steiner, Rudolf. 2001. Seelenübungen I. Dornach: Rudolf Steiner Verlag, vol. GA 267.

Steiner, Rudolf. 2008. Esoterische Unterweisungen Für Die Erste Klasse Der Freien Hochschule Für Geisteswissenschaft. Dornach: Rudolf Steiner Verlag, vol. GA 270c.

Steiner, Rudolf. 2013. Schriften. Kritische Ausgabe. Edited by Christian Clement. Stuttgart: Frommann-Holzboog. Tashakkori, Abbas, and Charles Teddlie. 2010. Sage Handbook of Mixed Methods in Social E Behavioral Research, 2nd ed. Los Angeles: The SAGE Publishing Ltd. [CrossRef]

Taves, Ann. 2011. Religious Experience Reconsidered. A Building Block Approach to the Study of Religion and Other Special Rhings. Princeton: Oxford University Press.

Taylor, Charles. 2012. Sources of the Self. The Making of Modern Identity. Cambridge: Harvard University Press.

Teddlie, Charles, and Fen Yu. 2007. Mixed Methods Sampling: A Typology with Examples. Journal of Mixed Methods Research 1: 77-100. [CrossRef]

Tewksbury, Richard. 2015. Studying Deviance. Qualitative Methods. In The Handbook of Deviance. Chichester: Wiley-Blackwell, pp. 210-24.

Traub, Hartmut. 2011. Philosophie Und Anthroposophie. Stuttgart: Kohlhammer.

Tremmel, Michael, and Ulrich Ott. 2017. Negative Wirkungen von Meditation. In Spiritualität und spirituelle Krisen. Stuttgart: Schattauer, pp. 233-43.

Tücher, Roland. 2018. Briefwechsel zwischen Anna-Katharina Dehmelt Und Irene Diet. Ein Nachrichtenblatt PLUS XII: $1-16$.

Velmans, Max. 2000. Investigating Phenomenal Consciousness. New Methodologies and Maps. Amsterdam: John Benjamins Publishing Company.

Vischer, Friedrich Theodor. 1889. Altes Und Neues. Stuttgart: Bonz.

Wagemann, Johannes. 2011. Meditation-Untersuchungsgegenstand, Forschungsmittel Und Entwicklungsweg. RoSE -Research on Steiner Education 2: 50-65.

Weger, Ulrich, and Friedrich Edelhäuser. 2014. The Role of the Brain During Conscious Experience: In Search of a New Metaphor. Journal of Conscious Studies 21: 111-29.

Weger, Ulrich, and Johannes Wagemann. 2015. The Behavioral, Experiential and Conceptual Dimensions of Psychological Phenomena: Body, Soul and Spirit. New Ideas in Psychology 39: 23-33. [CrossRef]

Wiebe, Phillip H. 2015. Intuitive Knowing as a Spiritual Experience. New York: Palgrave Macmillan.

Williams, Paul. 2004. Bodhi (Awakening). In Encyclopedia of Buddhism. New York: Macmillan Reference USA.

Williams, Paul, Anthony Tribe, and Alexander Wynne. 2012. Buddhist Thought: A Complete Introduction to the Indian Tradition. New York: Routledge.

Zajonc, Arthur. 2009. Meditation as Contemplative Inquiry. When Knowing Becomes Love. Great Barrington: Lindisfarne Books.

Zander, Helmut. 2007. Anthroposophie in Deutschland. Göttingen: Vandenhoeck und Ruprecht.

(C) 2018 by the author. Licensee MDPI, Basel, Switzerland. This article is an open access article distributed under the terms and conditions of the Creative Commons Attribution (CC BY) license (http://creativecommons.org/licenses/by/4.0/). 